\author{
Military Technical College \\ Kobry El-Kobbah, \\ Cairo, Egypt.
}

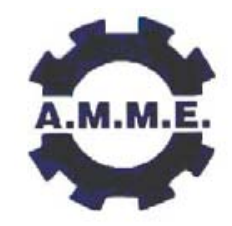

$13^{\text {th }}$ International Conference on Applied Mechanics and Mechanical Engineering.

\title{
ENHANCEMENT OF WEAR RESISTANCE OF DIE STEEL BY DEEP CRYOGENIC TREATMENT
}

\author{
DAS $^{*}$ D., DUTTA** A.K. and RAY ${ }^{* * *}$ K.K.
}

\begin{abstract}
A comparative study of the wear behavior of deep cryogenically treated vis-à-vis conventionally treated AISI D2 steel has been made to critically examine the extent of improvement in wear resistance of tool steels by cryotreatment. A series of experiments have been done to determine dry sliding wear resistance together with examinations of the worn surfaces and generated debris, characterization of the microstructures, and measurement of the hardness values of the differently heat treated steels. The obtained results unambiguously assist to infer that cryotreatment substantially improves wear resistance of D2 steel, but the extent of improvement is a strong function of the test load. These observations have been explained with appropriate identification of the operative wear mechanisms at different test conditions. Microstructural characterizations reveal that the improvement in hardness and wear resistance by cryotreatment is due to near complete removal of soft retained austenite with concurrent increase in the amount of secondary carbides and tempered martensite.
\end{abstract}

\section{KEY WORDS}

Deep cryogenic treatment, AISI D2, Wear resistance, Wear mechanisms, Microstructures,

Senior Lecturer, Department of Metallurgy and Materials Engineering, Bengal Engineering and Science University, Shibpur, Howrah - 711103, India.

** Professor, Department of Mechanical Engineering, Bengal Engineering and Science University, Shibpur, Howrah - 711103, India.

*** Professor, Department of Metallurgical and Materials Engineering, Indian Institute of Technology, Kharagpur - 721302, India. 


\section{INTRODUCTION}

Widespread use of near-net-shape processing of high-strength materials for the manufacturing industry has directed several endeavors to enhance the life of die steels by improving their wear resistance. One of the approaches to achieve improved wear resistance of die steel is the employment of deep cryogenic treatment in conjunction with conventional heat treatment [1-5]. Deep cryogenic treatment (148-77 K), commonly referred to as cryotreatment, is completely different from age-old cold treatment (213$93 \mathrm{~K})[1,6]$. Cryotreatment consists of controlled cooling of hardened specimens to cryogenic temperature, holding at that temperature for sufficiently long duration (12-72 h) and finally heating back to ambient temperature at a controlled rate for subsequent tempering $[1,6-8]$.

The benefit of cryotreatment for the enhancement of wear resistance of tool steels has been reported by several investigators [1-12] and this has been attributed to the reduction of retained austenite [5, 9] and/or precipitation of ultrafine carbides [4, 6-8] by cryotreatment, without sufficient quantitative microstructural evidences. Thus, the metallurgical understanding behind the improvement of wear resistance by cryotreatment is not yet crystallized. Furthermore, the reported increment in wear resistance due to cryotreatment also varies widely, i.e.; from a few percent to few hundred percent for the same material [2, 6, 10, 11]. For example, the reported improvements in the wear resistance of AISI D2 steel by cryotreatment are approximately $108 \%$ by Collins and Dormer [4], $817 \%$ by Barron [5], 70 to $600 \%$ by Meng et al. [3] and 160 to $2290 \%$ by Das et al. [6]. Such inconsistent reports and the lack of scientific understanding are hindering the commercial exploitation of the cryotreatment process, in spite of its remarkable potential to enhance the useful service life of tools/dies [2, 11]. The present investigation aims to resolve this controversy related to the extent of improvement in wear resistance of tool steels by cryotreatment through a comparative analyses of wear behavior of cryotreated vis-à-vis conventionally treated AISI D2 steel. This study also aims to reveal the metallurgical phenomena responsible for the enhancement in wear resistance of tool steel by cryotreatment.

\section{EXPERIMENTAL PROCEDURES}

The chemical composition of the investigated steel is shown in Table 1 and this conforms to the AISI specification of D2 steel. Steel specimens of approximate size of $24 \times 16 \times 85 \mathrm{~mm}$ were subjected to conventional treatment (QT) and deep cryogenic treatment (QCT) in separate batches; QT consists of hardening (Q) and single tempering (T), while QCT incorporates an additional step of controlled deep cryogenic processing $(\mathrm{C})$ in-between hardening and tempering. The cryogenic processing was performed at $77 \mathrm{~K}$ for $84 \mathrm{~h}$ in a laboratory made manually controlled cryogenic processor using liquid nitrogen as the cooling medium. Cooling/heating was controlled at a uniform rate of $45 \mathrm{~K} / \mathrm{h}$. The temperature control at each stage of heat treatment was $\pm 2 \mathrm{~K}$. Details of hardening and tempering treatments and the actual timetemperature profile of the cryogenic processing are presented in Fig. 1.

Specimens of suitable size and shape were machined from the heat-treated steel blocks by using wire-cut EDM (EUROCUT: MARK I) for different tests. Microstructural examinations were carried out using optical (Carl Zeiss: Axiovert 40 MAT) and scanning electron (SEM, Jeol: JSM-5510) microscopy on the polished and picral (3 gm picric acid 
in $100 \mathrm{ml}$ ethanol) etched specimens. Identification of the different phases and the measurement of retained austenite $\left(\gamma_{R}\right)$ content in the heat treated specimens were done following ASTM standard E975-00 [13] by x-ray diffraction (XRD) analyses using a PHILIPS PW 1830 X-ray diffractometer in Mo- $K_{\alpha}$ radiation on bulk polished specimens. The volume fraction of primary carbides (PCs) and secondary carbides (SCs) were measured with the help of Leica QMetals software considering 50 digital micrographs of each type of specimens as per standard stereological practices [14].

The macro- and micro- hardness values of the QT and QCT specimens were measured at $60 \mathrm{kgf}$ load and at $50 \mathrm{gf}$ load, respectively using Vickers indenter. At least ten readings were considered for macrohardness measurement, whereas a minimum of fifty readings were taken to estimate the average microhardness values of the material matrix. Sliding wear tests were performed according to ASTM standard G99-05 [15] by using a computerized pin-on-disc wear testing machine (DUCOM: TR 20). Cylindrical specimens of $4 \mathrm{~mm}$ diameter and $30 \mathrm{~mm}$ length were used as static pins; the rotating counter face was made of WC-coated En-35 steel disc (surface hardness $\approx 17.2 \mathrm{GPa}$ ) with roughness value of $R_{a}<0.5 \mu \mathrm{m}$. The faces of pin specimens were mechanically polished using up to $1 \mu \mathrm{m}$ diamond paste, cleaned in acetone in an ultrasonic cleaner and dried prior to wear tests. The wear tests were carried out at three different normal loads: $29.43 \mathrm{~N}$ (3 kgf), $58.86 \mathrm{~N}$ (6 kgf) and $88.29 \mathrm{~N}$ (9 kgf) at a constant linear sliding velocity of $2 \mathrm{~m} / \mathrm{s}$ in dry condition at the room temperature of $\sim 300 \mathrm{~K}$ and $60 \%$ relative humidity. The wear rates were measured by volume loss method from the recorded cumulative height loss of the specimens with respect to sliding distance in the steadystate wear regime by taking the average of at least three test results under identical conditions. The worn-out surfaces and the generated wear debris were subsequently examined using SEM coupled with energy dispersive X-ray (EDX, NORAN: Super DryII) microanalyses to identify the possible mode and mechanisms of wear.

\section{RESULTS AND DISCUSSION}

The results of this study are broadly categorized under three groups related to: (i) microstructure, (ii) hardness and (iii) wear behavior of the differently treated specimens. The salient features of these results and their pertinent discussions are presented below.

\section{Microstructural Characterization}

Typical optical microstructures for QT and QCT specimens are shown in Fig. 2. These micrographs exhibit non-uniform distribution of large elongated white regions of dendritic type primary carbides (PCs) and uniform distribution of numerous small, nearly spherical white secondary carbides (SCs) in tempered martensite matrix with revelation of prior austenite grain boundaries. In addition, there exist a large number of tiny black patches in both the microstructures (Fig. 2); these are sub-micron sized SCs. The morphology and distribution of PCs in both QT and QCT specimens are nearly identical, but the number of SCs appears to be much higher and more uniformly distributed in QCT specimen compared to that in QT specimen. Figure 3 depicts the XRD line profiles of bulk specimens for both QT and QCT samples. The nature of PCs and SCs are identified mainly as $\mathrm{M}_{7} \mathrm{C}_{3}$ and $\mathrm{M}_{23} \mathrm{C}_{6}(\mathrm{M}=\mathrm{Cr}$, Fe, Mo and $\mathrm{V})$ respectively from the XRD analyses (Fig. 3a); this is in good agreement with some reported results 
on D2 steel [16]. The characteristic diffraction peaks of $\gamma_{R}$, such as (220) and (311), are observed only in bulk specimens of QT sample; while the intensity of (211) diffraction peak of martensite phase is higher for QCT specimen than that for QT specimens (Fig. $3 b)$. These results suggest that deep cryogenic processing immediately after hardening transforms $\gamma_{R}$ almost completely to martensite in D2 steel. Figure 4 compares the amount of different microstructural constituents for QT and QCT specimens as measured by image analyses of micrographs and XRD analyses. It can be inferred from Fig. 4 that cryotreatment significantly increases the amount of SCs by $50.4 \%$ and tempered martensite by $7.9 \%$; while the $\gamma_{R}$ content decreases from 9.8 vol.\% in QT specimen to 0.4 vol.\% in QCT specimen. However, the content of PCs remains unaffected by cryogenic processing; this is expected since only the time and temperature of austenitization process can affect it and these parameters are identical for both QT and QCT specimens in this investigation (Fig. 1).

Steels with high carbon and high alloying elements, like D2 steel, have characteristic martensite finish temperature $\left(\mathrm{M}_{\mathrm{f}}\right)$ well below the ambient temperature. Thus, rapid cooling of these steels after austenitization to ambient temperature in conventional hardening treatment fails to convert all the austenite to martensite; as a result of which larger amount of $\gamma_{R}$ remains in those steels in the as-hardened condition [1]. Cryotreatment, where samples are cooled from ambient temperature to $77 \mathrm{~K}$ (Fig. 1), immediately after hardening, promotes continuation of conversation of $\gamma_{R}$ to martensite and thus almost completely eliminates the $\gamma_{R}$ from the microstructure. Complete conversion of austenite to martensite, in the subsequent tempering process, increases the amount of SCs and tempered martensite. From the present results, it can be concluded that the cryogenic treatment does not alter the nature and type of microstructural constituents, but almost completely removes the soft $\gamma_{R}$ with consequent increases in the amount of hard phases, like SCs and tempered martensite.

\section{Hardness}

The hardness values of QT and QCT specimens (Fig. 5) indicate that deep cryogenic treatment increases both the macrohardness $(8.3 \%)$ and microhardness $(10.2 \%)$ of D2 steel compared to the conventional treatment. These observations are in general agreement with several earlier reports [4-7]. For example, Molinari et al. [7] have reported $7 \%$ and $6.4 \%$ improvement of microhardness values by cryogenic treatment of M2 and H13 steels, respectively. The lower macrohardness of QT specimens is expected because of its higher content of soft $\gamma_{R}$ and lower content of hard SCs (Fig. 4). It is difficult to discern the role of $\gamma_{R}$ on the microhardness of its matrix but it appears that $\gamma_{R}$ accommodates some amount of the residual stress generated due to precipitation of carbide particles and thus leads to lower microhardness values for QT specimens. Furthermore, the microhardness values do not represent hardness of the matrix only; rather these values are significantly influenced by the amount of the finer SC particles. Therefore, the improvement of microhardness values by deep cryogenic treatment can be considered to originate from the contribution due to the precipitation of higher amount of SCs and martensite in the QCT specimen as compared to QT specimen. 


\section{Wear Behavior}

\section{Wear resistance}

The wear resistance $\left(W_{R}\right)$ of tool steels is a complex function of normal load, sliding velocity and hardness of the test specimens [17]. Therefore, the $W_{R}$ has been estimated in the present study as a non-dimensional parameter employing the relationship [8]:

$$
W_{R}=\frac{F S_{v}}{V_{L} H_{V}}
$$

where, $F$ is the normal load in $\mathrm{N}, S_{V}$ is the linear sliding velocity in $\mathrm{m} / \mathrm{s}, V_{L}$ is the wear volume loss of the test specimens in $\mathrm{m}^{3} / \mathrm{s}$ and $H_{V}$ is the Vickers hardness values of the pin specimens in $\mathrm{N} / \mathrm{m}^{2}$.

The estimated $W_{R}$ for both QT and QCT specimens for different $F$ values at a constant $S_{V}(2 \mathrm{~m} / \mathrm{s})$ are shown in Fig. 6a. The results in Fig. 6a reveal that the $W_{R}$ of QCT specimens are considerably higher than that for QT specimens over the entire range of $F$ values $(29.43$ - $88.29 \mathrm{~N})$. This observation is consistent with several earlier investigations [3-12], which report that cryotreatment substantially improves the $W_{R}$ of tool steels. However, the observed $W_{R}$ values for QCT and QT specimens are significantly dependent on the magnitude of $F$. For example, the values of $W_{R}$ for $Q T$ and QCT specimens are 63 and 130 at $F=88.29 \mathrm{~N}$ and 160 and 6242 at $F=58.86 \mathrm{~N}$, respectively. In addition, the estimated $W_{R}$ for both the specimen decreases with increase in the magnitude of $F$, which is in general agreement with the wear behavior of materials that $W_{R}$ decreases with increasing severity of test conditions [17]. Interestingly, the dependence of $W_{R}$ on $F$ is found to be considerably higher for $Q T$ specimens as compared to QCT specimens (Fig. 6a).

The improvement in $W_{R}$ by cryogenic treatment over conventional treatment $(\alpha)$ at a given $F$ value has been calculated using the following relationship:

$$
\alpha=\frac{W_{R}^{Q C T}-W_{R}^{Q T}}{W_{R}^{Q T}}
$$

where, $W_{R}^{Q C T}$ and $W_{R}^{Q T}$ are $W_{R}$ of QCT and QT specimens, respectively. The calculated values of $\alpha$ for different $F$ values are depicted in Fig. 6b. The values of $\alpha$ is found to be strongly dependent on magnitude of $F$ and it is maximum at an intermediate value of $F$ (Fig. 6b). The values of $\alpha$ are 76 and $106 \%$ for $F$ values of 29.43 and $88.29 \mathrm{~N}$, respectively; whereas its magnitude at $F=58.86 \mathrm{~N}$ is higher by two orders of magnitude $(3801 \%)$. The obtained results lead to conclude that the cryotreatment improves the $W_{R}$ of D2 steel substantially but the degree of improvement varies from a few percent to a few hundred percent depending on the values of $F$ employed in the wear tests. The wide variation in the values of $\alpha$ has earlier been reported with the variation of $S_{v}$ by Meng et al. [3] and $F$ by Das et al. [6]. 


\section{Wear mechanisms}

In order to reveal the underlying mechanism/mechanisms responsible for the wide variation of $\alpha$ with $F$, the worn surfaces and the generated wear debris for both QT and QCT specimens have been examined under SEM with associated EDX microanalyses. The morphologies of the worn surfaces for QT and QCT specimens are compared in Fig. 7 for all the investigated wear conditions. Whereas, typical representative SEM photographs of wear debris collected in the steady-state wear regime and their EDX spectra are depicted in Fig. 8 for both QT and QCT specimens subjected to wear test at $F=58.86 \mathrm{~N}$. The general morphologies of worn surfaces for both QT and QCT specimens are nearly identical when wear tests have been carried out at lower (Fig. 7a vis-à-vis Fig. 7b) or at higher (Fig. 7e vis-à-vis Fig. 7f) loads. However, the damage on the worn surfaces appears to be more severe for QT specimens than that on QCT specimens (Fig. 7), which are in agreement with the measured $W_{R}$ for these specimens (Fig. 6a). The worn surfaces of both QT and QCT specimens are almost fully covered with loose as well as compacted oxides at $F=29.43 \mathrm{~N}$ (Figs. $7 \mathrm{a}$ and $7 \mathrm{~b}$ ), while the same at $F=88.29 \mathrm{~N}$ are rough and metallic in nature with significant presence of fractured ridges (Figs. 7e and 7f). Analyses of the worn surfaces suggest that the mechanisms of wear amongst the differently treated specimens are identical, i.e., oxidative [18] at lower (29.43 N) and delaminative [19] at higher (88.29 N) loads. Under these conditions of wear tests, the estimated values of $\alpha$ varies from $76-106 \%$ (Fig. 6b). Interestingly, wear mechanisms changes from oxidative to delaminative with the variation of $F$ that resulted into significant reduction in the measured $W_{R}$ values for both QT and QCT specimens (Fig. 6a). The morphologies of worn surfaces at the intermediate $F$ value $(58.86 \mathrm{~N})$, however, are remarkably different for QT and QCT specimens (Fig. 7c vis-à-vis Fig.7d). While worn surface of QT specimen is rough and metallic in nature (Fig. 7c), the same for QCT specimen is smoother and fully covered by oxides (Fig. 7d). The related morphologies of wear debris and their EDX spectra reveal that the wear debris of QT specimens are large platelets (Fig. 8a) of metallic nature (Fig. 8c), while the wear debris of QCT specimens are extremely fine granular (Fig. 8b) of oxide types (Fig. 8d). These observations indicate that the wear mechanism are different for QT and QCT specimens at $F=58.86 \mathrm{~N}$, and these indicate oxidative wear for QCT specimens and delaminative wear for QT specimens. The change of wear mechanism is known to vary the wear rates over order of magnitudes [17] and is considered to be the cause for the abnormally higher estimated value of $\alpha(3801 \%)$ at $F$ $=58.86 \mathrm{~N}$ (Fig. 6b). From the above observations, it can be concluded that the wide variation of $\alpha$ values as estimated in the present investigation and as reported earlier by several investigators $[3,6,10,11]$ is due to the similar or dissimilar active wear mechanisms in the specimens with or without cryotreatment.

Estimated $W_{R}$ (Fig. 6a) in conjunction with the results of microstructural analyses (Fig. 4) for QT and QCT specimens unambiguously reveals that the improvement of $W_{R}$ by cryotreatment is due to the near complete removal of $\gamma_{R}$ with concurrent increase in the amount of SCs and tempered martensite. Removal of soft $\gamma_{R}$ increase the plastic deformation induced delaminative wear to higher loads [17, 19] as observed for QCT specimens than that for QT specimens at $F=58.86 \mathrm{~N}$ (Fig. 8). While, more uniform distribution (Fig. 2) and higher amounts of SCs (Fig. 4) increase the crack growth resistance and load bearing capability of the tool steels [6, 16], increased amount of tough tempered martensite increases resistance of the matrix against pull-out of hard carbides, specifically for the larger PCs, during the course of wear. Thus the favorable microstructural modifications by cryotreatment enhance the $W_{R}$ of D2 steel. 


\section{CONCLUSIONS}

The following major conclusions can be derived from the experimental results and the analyses presented in this study.

1. Imposition of deep cryogenic processing in-between conventional hardening and tempering treatments substantially improves the wear resistance of D2 steel under all investigated normal loads in the dry sliding wear tests. However, the degree of improvement in wear resistance by cryotreatment (QCT) over conventional treatment (QT) is strongly dependent on the applied load that determines whether the operative wear mechanism for both QT and QCT specimens would be similar or dissimilar.

2. When the operative wear mechanisms for both QT and QCT specimens are identical, i.e., oxidative at a load of $29.43 \mathrm{~N}$ and delaminative at a load of 88.29 $\mathrm{N}$, the improvements in wear resistance by cryotreatment are $76 \%$ and $106 \%$, respectively. In contrast, the improvement in wear resistance by cryotreatment at a load of $58.86 \mathrm{~N}$ is over an order of magnitude where the operative wear mechanisms are found to be different for QT and QCT specimens; i.e., oxidative for QCT specimens and delaminative for QT specimens.

3. Correlation of hardness values and wear resistance with concerned microstructures for specimens with or without cryotreatment reveals that the improvement in hardness and wear resistance by cryotreatment is due to near complete removal of soft retained austenite with concurrent increase in the amount of hard secondary carbides and tough tempered martensite.

\section{ACKNOWLEDGMENTS}

The financial assistance received from the University Grants Commission, Government of India [Grant no. F. No. 31-48/2005(SR)] to carry out a part of this research is gratefully acknowledged.

\section{REFERENCES}

[1] Carlson, E.A., "Cold Treating and Cryogenic Treatment of Steel", in ASM Handbook, Vol. 4, Heat Treating, $10^{\text {th }}$ ed., ASM International, Metals Park, Ohio, pp 203-206, (1990).

[2] Reitz, W. and Pendray, J., "Cryoprocessing of materials: a review of current status", Mater. Manuf. Process, Vol. 16, pp 829-840, (2001).

[3] Meng, F., Tagashira, K., Azuma, R. and Sohma,H., "Role of eta-carbide precipitations in the wear resistance improvements of Fe-12Cr-Mo-V-1.4C tool steel by cryogenic treatment", ISIJ Int., Vol. 34, pp 205-210, (1994).

[4] D.N. Collins, J. Dormer, Deep cryogenic treatment of a D2 cold-worked tool steel, Heat Treat. Met., Vol. 3, pp 71-71, (1997).

[5] R.F. Barron, R.F., "Cryogenic treatment of metals to improve wear resistance", Cryogenics, Vol. 22, pp 409-413, (1982).

[6] Das, D., Dutta, A.K., Toppo, V. and Ray, K.K., "The Effect of cryogenic treatment on the carbide precipitation and tribological behavior of D2 steel", Mater. Manuf. Process, Vol. 22, pp 474-480, (2007). 
[7] Molinari, A., Pellizzari, M., Gialanella, S., Straffelini, G. and Stiasny, K.H., "Effect of deep cryogenic treatment on the mechanical properties of tool steels", J. Mater. Proc. Tech., Vol. 118, pp 350-355, (2001).

[8] Bensely, A., Prabhakaran, A., Mohan Lal, D. and Nagarajan, G., "Enhancing the wear resistance of case carburized steel (En 353) by cryogenic treatment", Cryogenics, Vol. 45, pp 747-754, (2005).

[9] Kamody, D.J., "Using deep cryogenics to advantage", Adv. Mater. Process, Vol. 10, pp 215-218, (1998).

[10] Kalin, M., Leskovšek, V. and Vižintin, J., "Wear behavior of deep-cryogenic treated high-speed steels at different loads", Mater. Manuf. Process, Vol. 21, pp 741-746, (2006).

[11] Zurecki, Z., "Cryogenic quenching of steel revisited", In: Proceedings of the $23^{\text {rd }}$ ASM Heat Treating Society Conference, (ASM, Pennsylvania, 2005), Eds.: D. Herring and R. Hill, ASM Proceedings: Heat Treating (2006) p. 106.

[12] Liu, H.H., Wang, J., Shen, B.L., Yang, H.S., Gao, S.J. and Huang, S.J., "Effects of deep cryogenic treatment on property of 3Cr13Mo1V1.5 high chromium cast iron", Mater. Design, Vol. 28, pp 1059-1064, (2007).

[13] ASTM E975-00: Standard Practice for X-Ray Determination of Retained Austenite in Steel with Near Random Crystallographic Orientation, ASTM Book of Standards, V 03.01, West Conshohocken, PA, United States, (2004).

[14] Underwood, E.E., Quantitative Stereology, Addison-Wesley, Reading, MA, (1970).

[15] ASTM G99-05: Standard Test Method for Wear Testing with a Pin-on-Disk Apparatus, ASTM Book of Standards, V 03.02, West Conshohocken, PA, United States, (2005).

[16] Fukaura, K., Yokoyama, Y., Yokoi, D., Tsujii, N. and Ono, K., "Fatigue of coldwork tool steels: effect of heat treatment and carbide morphology on fatigue crack formation, life, and fracture surface observations", Metall. Mater. Trans., Vol. 35A, pp 1289-1300, (2004).

[17] Lim, S.C. and Ashby, M.F., "Wear-mechanism maps", Acta Metall., Vol. 35, pp 1-24, (1987).

[18] Quinn, T.F.J., "Review of oxidational wear. I.-The origins of oxidational wear", Tribology Int., Vol. 16, pp 257-271, (1983).

[19] Suh, N.P, "The delamination theory of wear", Wear, Vol. 25, pp 111-124, (1973).

Table 1: Nominal composition of the investigated steel.

\begin{tabular}{|c|c|c|c|c|c|c|c|c|c|}
\hline Element & $\mathrm{C}$ & $\mathrm{Mn}$ & $\mathrm{Si}$ & $\mathrm{S}$ & $\mathrm{P}$ & $\mathrm{Cr}$ & $\mathrm{Mo}$ & $\mathrm{V}$ & $\mathrm{Fe}$ \\
\hline Weight (\%) & 1.49 & 0.29 & 0.42 & 0.028 & 0.029 & 11.38 & 0.80 & 0.68 & Balance \\
\hline
\end{tabular}




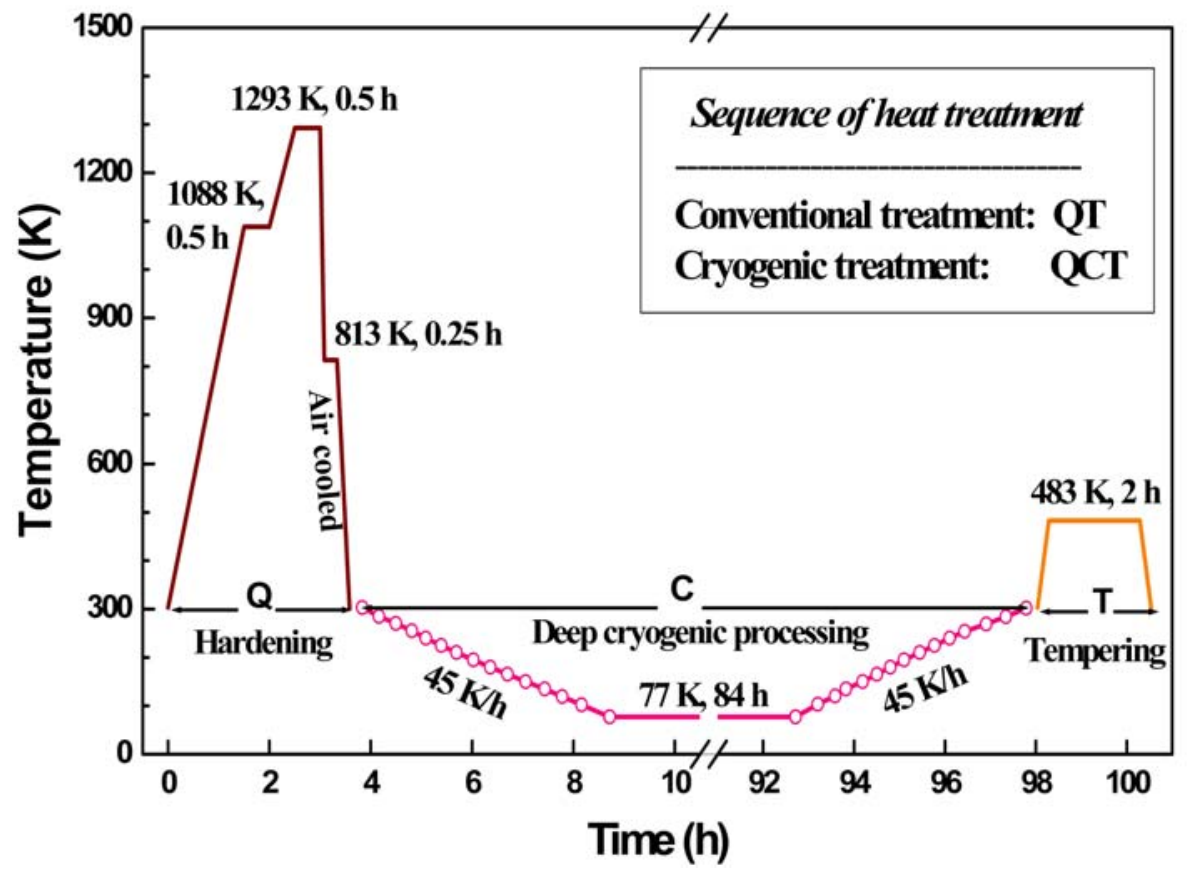

Fig. 1. Details of different heat treatment schedules.
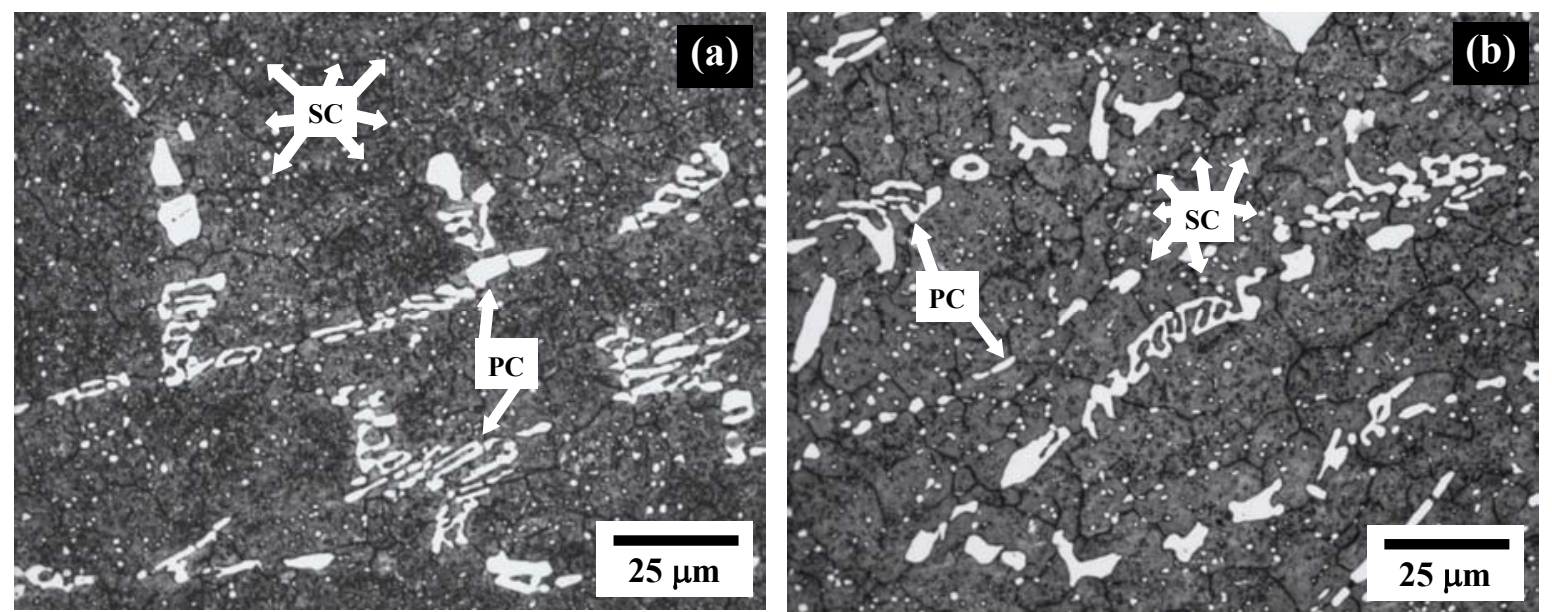

Fig. 2. Typical optical micrographs of (a) QT and (b) QCT specimens. Carbides: white; Tempered martensite: black; (PC - primary carbide, SC - secondary carbide). 

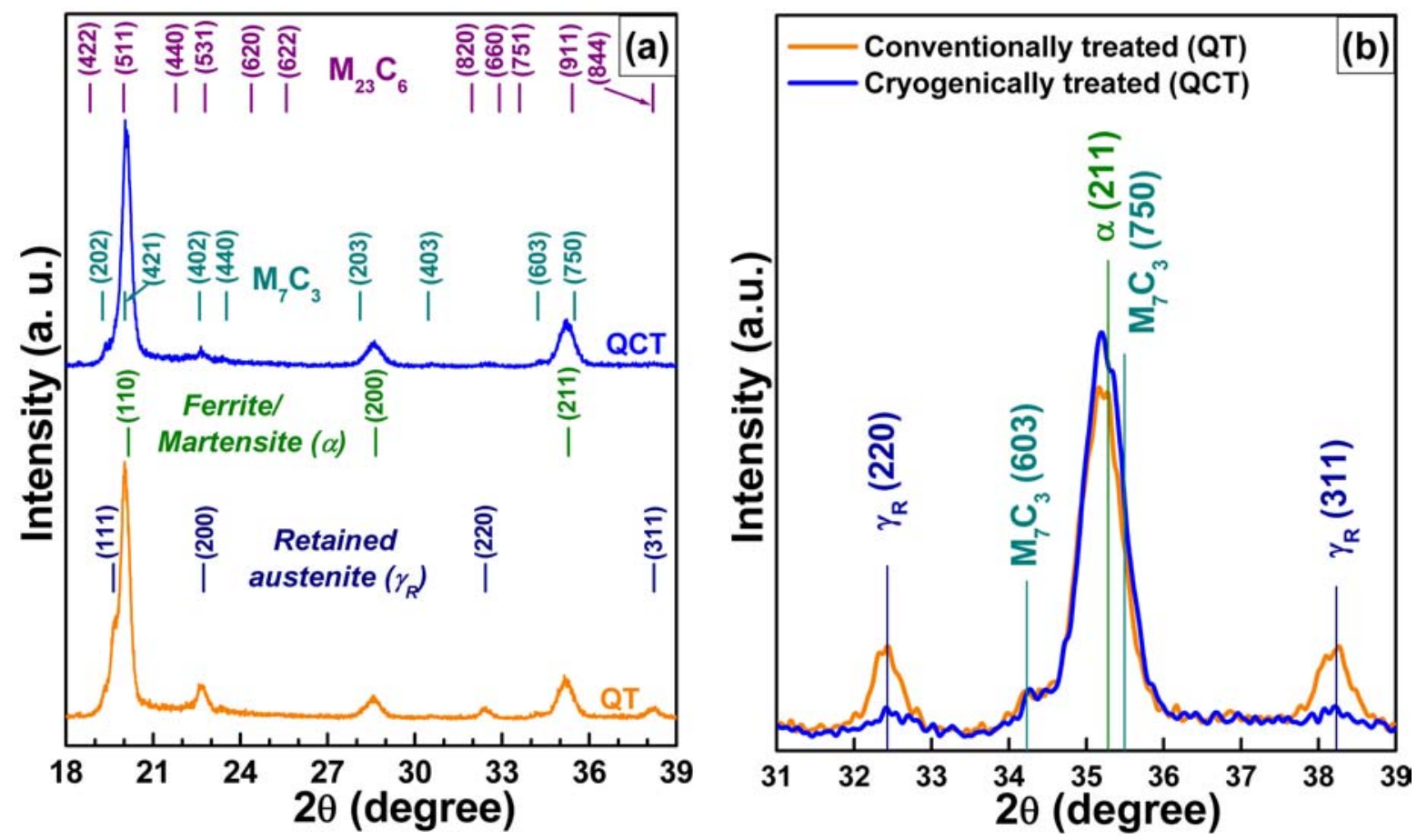

Fig. 3. XRD line profiles: (a) overall scanned view for identification of different phases and $(b)$ enlarged view $\left(2 \theta=31-39^{\circ}\right)$ showing the differences in the intensities of retained austenite and martensite phases in bulk samples of QT and QCT specimens.

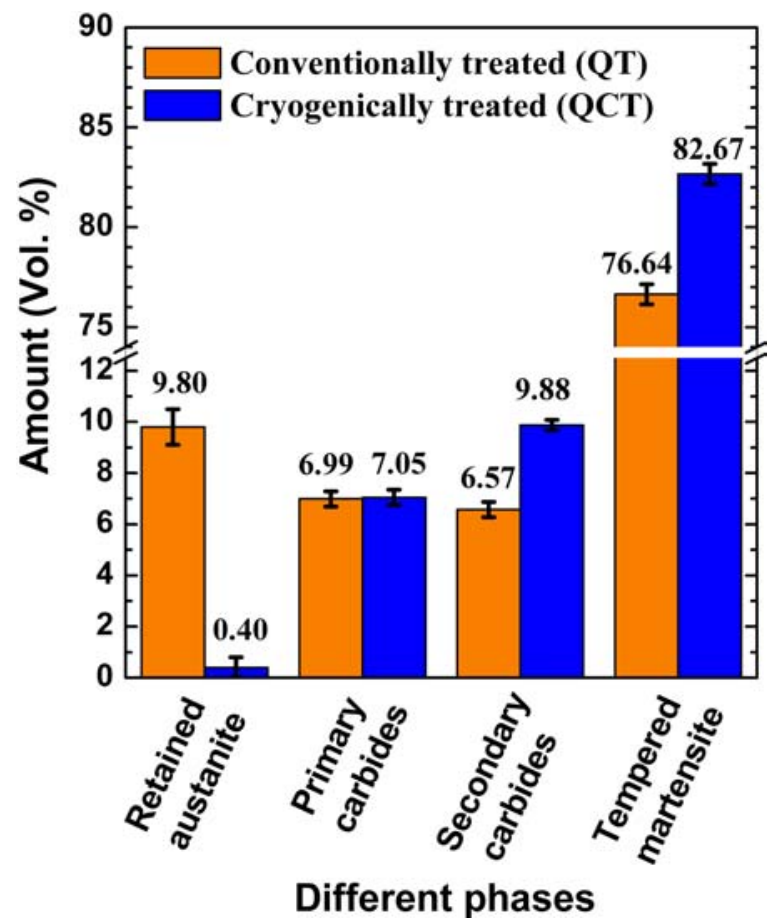

Fig. 4. Amount of different phases as obtained by image analysis and XRD technique for QT and QCT specimens.

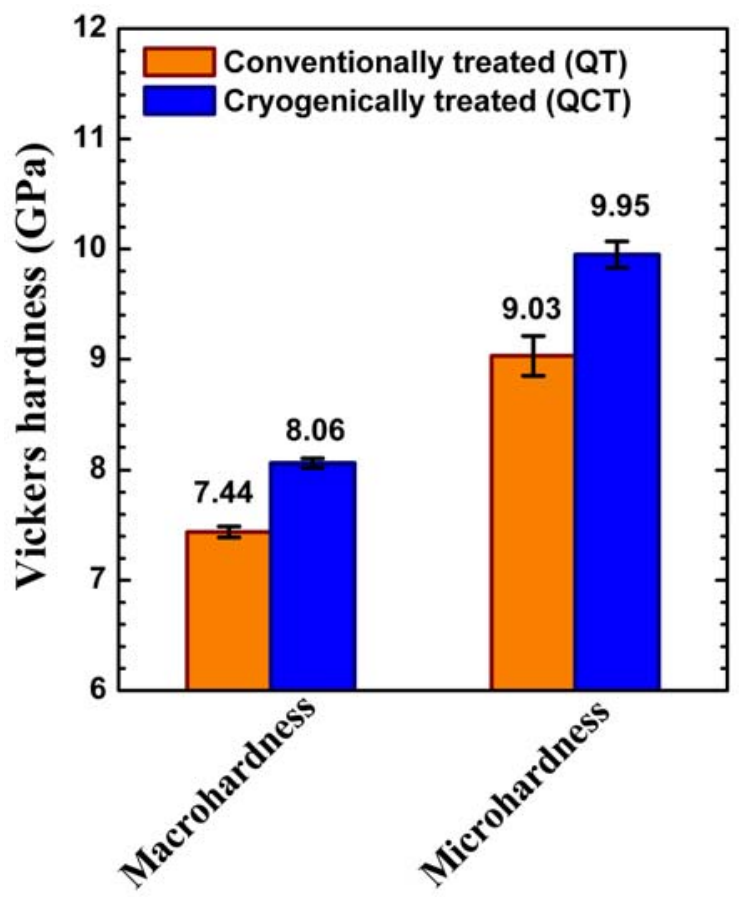

Fig. 5. Variations of measured macroand micro- hardness values for QT and QCT specimens. 

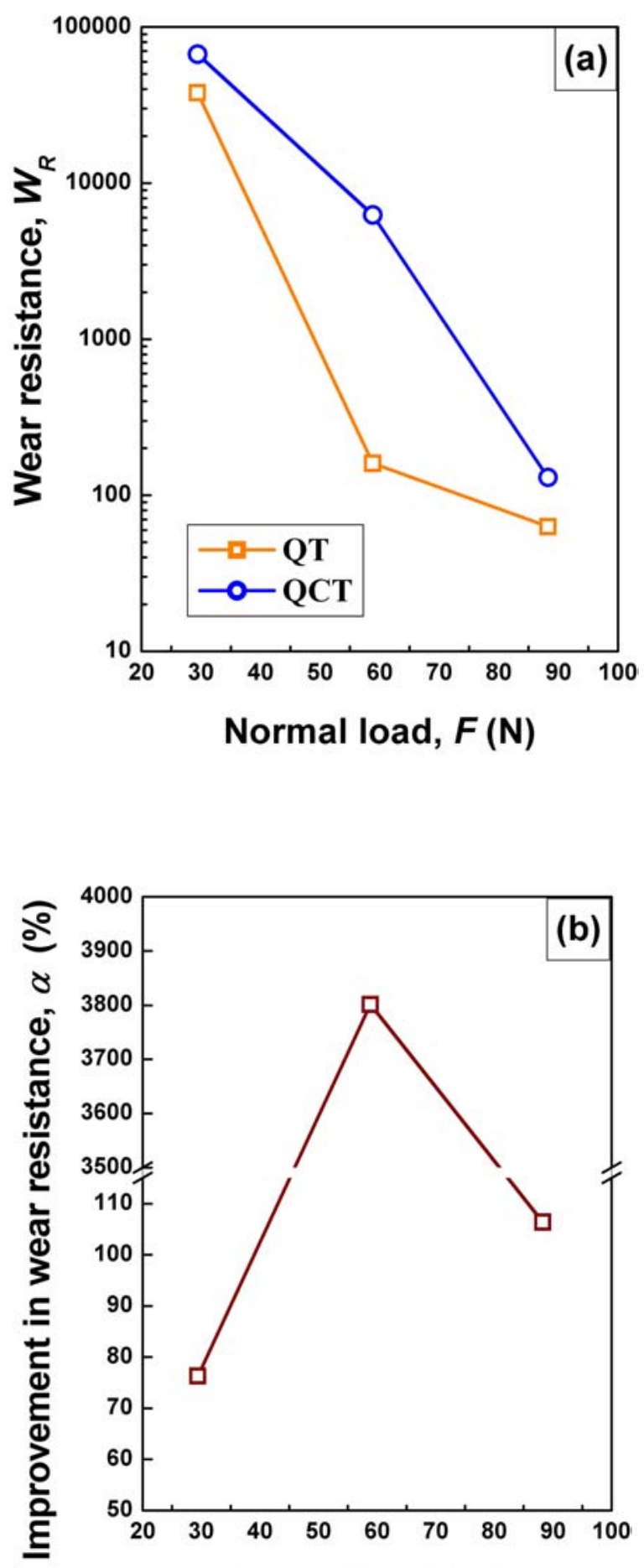

Normal load, $\boldsymbol{F}(\mathbf{N})$

Fig. 6. Estimated (a) wear resistance of QT and QCT specimens and (b) improvement in wear resistance by cryogenic treatment over conventional treatment with applied normal loads. 

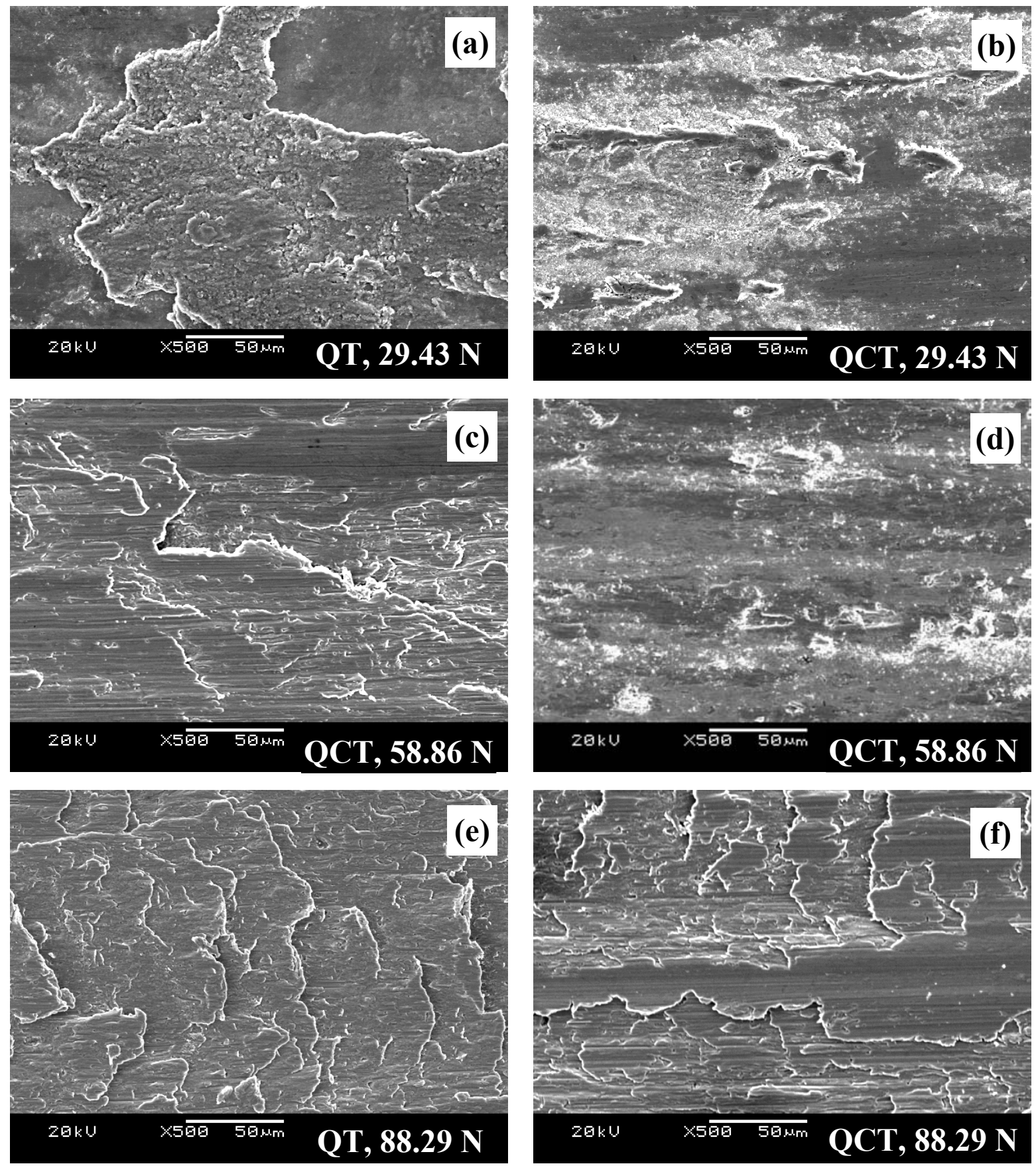

Fig. 7. Comparison of SEM micrographs of worn surfaces of QT (a, c, e) and QCT (b, d, F) specimens tested at normal load of $29.43 \mathrm{~N}(\mathrm{a}, \mathrm{b}), 58.86 \mathrm{~N}(\mathrm{c}, \mathrm{d})$ and 88.29 $N(e, f)$. 

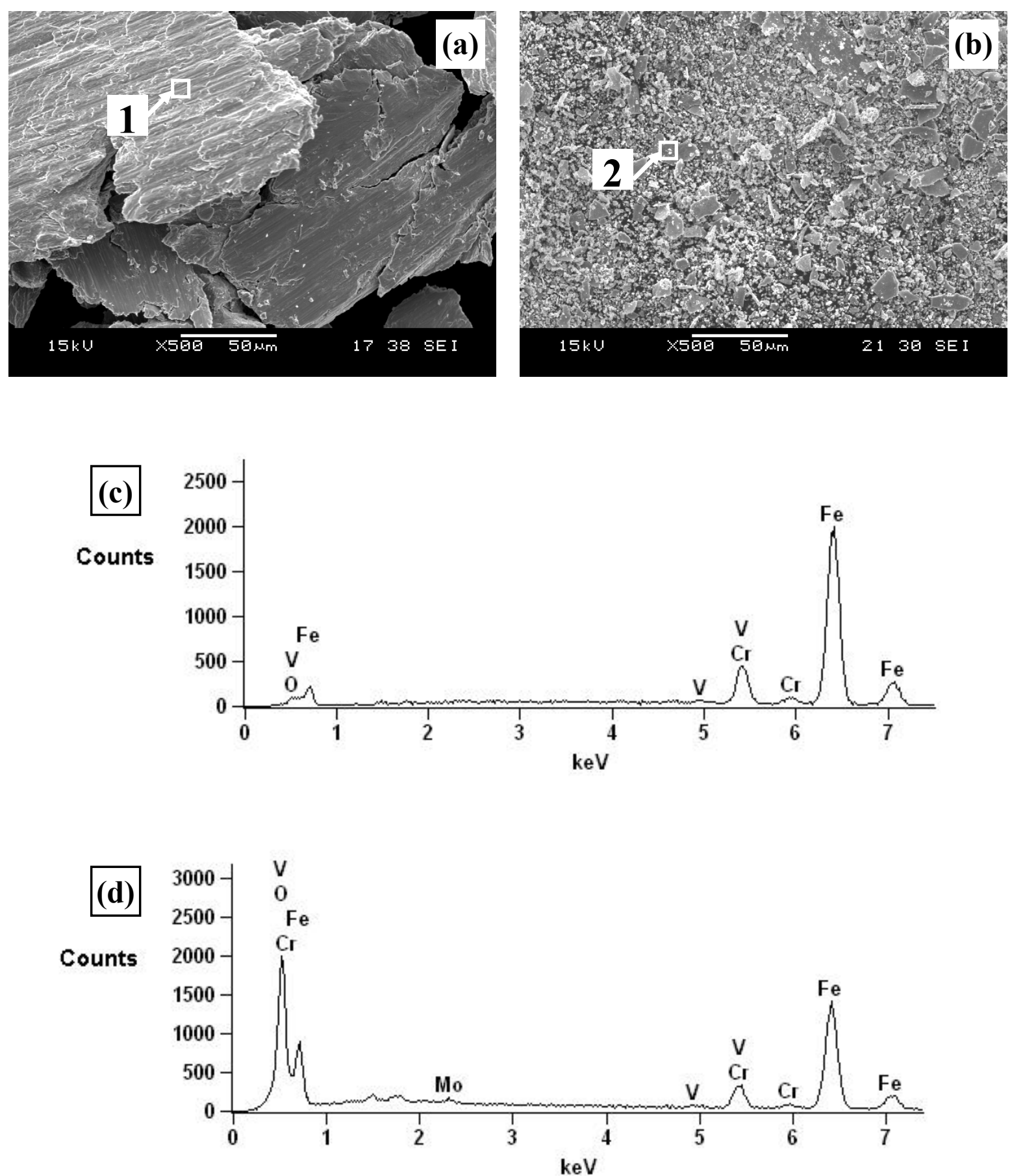

Fig. 8. Morphologies of wear debris: (a) QT and (b) QCT specimens subjected to wear tests at $58.86 \mathrm{~N}$. Figures (c) and (d) are EDX spectra taken from the debris marked as 1 in Fig. (a) and 2 in Fig. (b), respectively. 